Article

\title{
Joint Storage: A Mixed-Method Analysis of Consumer Perspectives on Community Energy Storage in Germany
}

\author{
Esther Hoffmann * and Franziska Mohaupt \\ Institute for Ecological Economy Research (IÖW), 10785 Berlin, Germany; franziska.mohaupt@ioew.de \\ * Correspondence: esther.hoffmann@ioew.de
}

Received: 30 April 2020; Accepted: 8 June 2020; Published: 11 June 2020

check for updates

\begin{abstract}
In this paper, we analyze consumer attitudes toward and interest in community energy storage (CES) in Germany, based on five focus group discussions and an online survey of private owners of photovoltaic (PV) systems, as well as written surveys and workshops with the residents of two residential developments where CES has been installed. We find that owners of PV systems are generally receptive to the idea of CES but are unfamiliar with it. They assume that CES is more resource- and cost-efficient than residential storage and appreciate the idea of professionally managed operation and maintenance, but are skeptical of whether fair and transparent distribution and billing can be realized. Consumers express a need for ancillary services, such as monitoring, information or energy management, but the interest in such services, however, is strongly dependent on their perception of the costs versus potential savings.
\end{abstract}

Keywords: energy storage; community storage; battery storage; consumer; user; prosumer; acceptance; energy services

\section{Introduction}

One option to increase the utilization of energy from volatile renewable sources is implementation of energy storage at the household level [1]. Homeowners often install such energy storage systems to enhance energy consumption from their own photovoltaic (PV) systems (self-consumption). Currently, residential storage is the dominant technical option [2] in Germany, and as of 2018, more than 100,000 residential storage systems have been installed [3]. Nevertheless, the ongoing integration of renewable power sources calls for more flexible solutions [4,5].

In the context of energy transition, local communities in cities, towns and villages worldwide are coming together to create their own future vision of how to achieve an energy supply based on 100 percent renewable energies, as well as other climate mitigation goals [6]. Many of these communities are engaged in diverse energy-related activities and projects [7], including in part the installation of community energy storage (CES), which provides greater flexibility, higher efficiency, and lower losses as compared to residential energy storage [8]. CES has the potential to strengthen the role of local communities and may generate collective benefits such as a higher penetration of renewables and increased self-consumption [9]. Most research dealing with CES deals solely with the technical or economic aspects (e.g., [8-11]), with little analysis given to the perceptions and acceptance of potential users-for exceptions, see [12,13] for municipalities and energy companies, or [14-17] for consumer views. Existing studies on consumer views were conducted without including consumers who have practical experience with community battery storage. Moreover, they mostly rely on a single research method or a combination of two methods. In contrast to these studies, we use a mixed method approach with an online survey, focus groups and research in two neighborhoods where residents had practical 
experience with CES systems. We examine the advantages and disadvantages of CES from a consumer viewpoint. CES can foster an increased sense of neighborhood belonging and common identity $[18,19]$, but it requires both organizational services and monitoring concepts. To date, only a few studies on CES and these ancillary energy services exist. We aim at filling this gap through studying consumer views on ancillary services that can be combined with CES systems. The consideration of consumer needs and viewpoints can help to improve these services.

Since future energy systems and new technologies may have characteristics that could conflict with basic human needs, such as autonomy and privacy [15], it is important to investigate their social acceptance. Given that the implementation of energy projects is generally a "community involvement issue" [20] (p. 828), an important insight has been that social acceptance is usually greater when user integration takes place at an early stage of the development process [21]. User integration is especially beneficial in the context of sustainable innovations that "often require changes in user behavior" [21] (p. 27). When key factors that can facilitate the adoption of these innovations are identified, it is possible to design new energy products "in a way that they may easily be integrated into users' habits and everyday life" [21] (p. 27). Furthermore, given the significance of small-scale investors as a necessary source of funding for a successful energy transition [22], it is important to develop business models that make private investment in CES attractive. This article deals with the acceptance of different storage solutions as well as the pros and cons of CES and related energy services. We consider the following research questions:

(1) What do PV system users expect from an energy storage system?

(2) What are the conditions under which they would be willing to invest in storage and ancillary services?

(3) Under which conditions would they favor CES over residential storage?

We focus on Germany, where the share of electrical power from renewable sources is close to the European average [23] and several CES pilot projects already exist. Electricity storage in Germany is presently attractive to consumers, as current regulations favor PV self-consumption over grid feed-in.

We set our analysis of CES acceptance within the greater conceptual framework of a discussion of technology acceptance in general, followed by a summary of two discussions in the literature that are relevant for our research: research on consumer preferences regarding storage technologies in general, and the role of energy services related to storage systems as well as respective community solutions. The following chapter summarizes the recent literature on these two issues.

\subsection{Dimensions of Technology Acceptance}

Whenever questions arise about the transition from one technological pathway to another, the acceptance of those affected must be considered [24]. According to Hildebrand et al. [25] and Schweizer-Ries et al. [26], technology acceptance has two dimensions: validation (positive to negative), and engagement (passive to active) (see Figure 1).

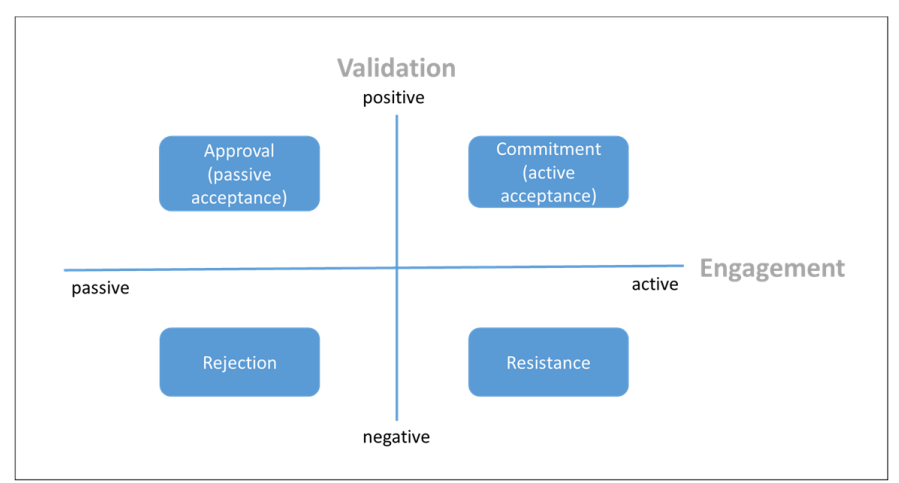

Figure 1. Dimensions of acceptance, translated and adapted from $[24,26]$. 
Among those who rate a technology positively, there is usually a group that approves of the technology but takes no further action (passive acceptance) [27]. Only when the willingness to act is transcended and individuals take observable action, such as making a personal investment in the technology [27], or its purchase and use [28], can one speak of active acceptance of a new technology [26]. In the case of energy transition, this active acceptance includes, for example, the installation of a PV system, thus, turning the consumer into a prosumer.

German consumers are being increasingly confronted with the growing number and decentralized distribution of renewable energy-based power plants [25,29]. Despite the rapid growth in numbers of such decentralized renewable energy plants within a relatively short period of time, a majority of the German population still approves of the energy transition [25,30]. To fully realize the transition, however, from a fossil fuel-based pathway to zero carbon, the mere absence of resistance, or even passive acceptance, will not suffice; active participation is often needed, i.e., commitment (upper right quadrant in Figure 1). To implement renewable and decentralized energy systems on a large scale, the need for active acceptance is inevitable. Hence, with regard to the acceptance of CES, we are mainly interested in those who generally approve of the idea but have not taken action by now (upper left quadrant in Figure 1). Therefore, we focus on how such active acceptance can be achieved.

\subsection{Consumer Perceptions Regarding Energy Storage}

Recent studies on the social acceptance of storage technologies in Europe and Australia have focused on the public's attitudes in general towards energy storage systems and their perception [15-17]. Specific insights into the determinants of active acceptance at the individual level, i.e., concrete action such as investment participation [24], remain scarce.

In the past few years, the topics of social acceptance and public perception of storage technologies [14,31], as well as consumer preferences [16], have received increasing attention in academia. While many researchers have focused on residential storage solutions [32-35], recently, interest in the public perception of CES has grown as well [36,37]. Some researchers have carried out comparative studies of the public perception of residential energy storage vs. community energy storage: Ambrosio-Albalà [14] discussed scenarios with residential and with community energy storage systems in focus groups and identified influencing factors for adopting residential vs. community battery storage. Kalkbrenner [16] analyzed preferences for different storage systems. MVV Energie AG et al. [38] conducted a field test with different models for storing electric energy and analyzed the perceptions of participants.

Participants in the abovementioned empirical studies (queried via focus groups $[14,15,38]$, semi-structured interviews [33], online surveys [31,34], choice experiments [16,32] and a field-test [38]) were usually open to engaging with energy storage technologies. They felt positively about the technology, believing that they would generally benefit from its deployment, either through the reduction in individual costs [14], because the technology would ensure a secure electricity supply, or strengthen their country's national economy [31]. Their main expectations were to increase their own self-consumption of renewable energy and realize savings in electricity costs [32,33,38]. Increased independence from electricity suppliers $[16,32,33,38]$ as well as protection against possible increases in electricity prices $[34,35]$ were also cited. Profitability would seem to be the dominant argument [14,31], yet current research suggests that investment in an energy storage system does not yet pay off financially $[11,39]$. Granted, investment in the combination of PV and energy storage can be fully amortized-although the payback period would be shorter without the storage-and investment in energy storage in combination with energy-saving measures does pay off [39]. In addition to economic arguments, ideological reasons, such as making a positive contribution to the energy transition [33-35], or more generally, to climate and environmental protection [32,34], play an important role-albeit, as supporting and not as standalone arguments.

Given that personal financial gain is one of the primary drivers, respondents in the studies viewed the associated costs of an energy storage system as a primary impediment $[14,18,32]$. 
Furthermore, some were not willing to engage in energy storage until the technology matures [32]. Ambrosio-Albalá et al. [14] also found that study participants who lived on property where they did not intend to reside for a longer period of time were unwilling to install an energy storage system. Other uncertainties about the future strengthened this attitude. Jones et al. [31] found that the acceptance of storage system depends on trust in the developers.

Kloppenburg et al. [17] characterized energy storage as having an ambivalent impact regarding an active role for citizens in the energy system. The technology supports householders in achieving greater independence from suppliers, but at the same time, it increases their dependence on intermediaries and the information technologies needed to steer and manage local storage.

Comparative studies dealing with acceptance of residential versus community energy storage have shown mixed results. Kalkbrenner [16] concluded that a potential market exists for both storage concepts, but that consumers prefer ownership over use rights. Ambrosio-Albalá [14] found that participants were skeptical about CES because of a tragedy of the commons dilemma and the fear of unequal usage; moreover, participants did not like the idea of a third party operating the CES system. They thus concluded that institutional design is important to create trust in the operator and that information should be provided on how fairness can be reached [14]. Participants in the survey conducted by MVV Energie AG et al. [38] preferred CES over residential storage. In focus groups, Soland et al. [15] found that study participants were in favor of CES because of safety and environmental concerns and doubts about the cost-value ratio of residential energy storage.

Since all of the CES solutions that exist today are pilot projects $[4,5,37,38]$, the approval ratings for community solutions must, for now, be considered primarily the evaluation of an idea. Hence, more insights are needed to better indicate and employ appropriate factors fostering community solutions.

\subsection{Energy Services for CES}

While recommendations have been developed for the design of services for end users in the smart grid [40], to date, no literature exists on smart energy services for CES. Kloppenburg et al. [17] mentioned that they were not able to include community driven storage solutions in their research because of the limited number of examples. Furthermore, in none of the studies evaluated were energy services for CES explicitly included in participant discussions. Nevertheless, some of the studies include statements by participants suggesting that they would only consider using such a system if certain energy services were offered along with it, i.e., monitoring and operation.

To establish trust, Schnabel and Kreidel [41] advocate that such services be offered by a professional third party. Ambrosio-Albalá et al. [14] found that participants would only want CES "if it could be guaranteed that the use would be equal and fair" (p. 145). There was a fear that some community members might exceed their fair share, and thus, the perceived need for an individual assessment of the energy performance of each community member [14]. In accordance with Schnabel and Kreidel [41], the systems that monitor energy flows and usage patterns must ensure the desired level of fairness and transparency and provide users with their specific energy use data as a basic service; furthermore, an overview of individual energy use is a prerequisite for forecasting and other energy services. With the information from monitoring, users have the opportunity to actively engage with their power consumption data and entertain suggestions for efficiency improvements [41]. Finally, such "information systems help to deliver customers the feeling of consuming self-produced electricity also at times when their PV module is not generating electricity" [5] (p. 498).

Several authors $[5,9,16,37,42]$ have dealt with the general structure of possible business models. Regarding potential operators of a community storage system, the studies mention utility companies, aggregators, energy service companies and housing companies-all of which would manage the entire local energy system including energy storage. Parra et al. state that "in this context, the development of new policies and business models including different services provided by CES and creating 
win-win situations for customers (who generate their own energy locally) and other stakeholders should be pursued" [42] (p. 744).

Summarizing the existing literature on the implementation of CES, it is clear that it is technically feasible to operate such systems. Although the findings are based exclusively on the results of pilot projects, it is also clear that an essential component of a successful operation is the monitoring and communication of energy flow data to the system users. Most studies consider ancillary services that allow for transparent monitoring of storage usage to be important.

While the focus so far has been on technical feasibility, there is a lack of assessment of consumer willingness to pay, motivation, and potential disincentives. Both the research and the practical implementation of necessary ancillary services related to energy and storage management are still in their infancy. Thus, we began our investigation with a close look at consumer attitudes toward and interests in CES and ancillary energy services.

In the following, we present a mixed-method analysis consisting of focus group discussions, an online survey, and research in two residential neighborhoods (survey, workshops) (Chapter 2). We present our results in Chapter 3: We first analyze general views on storage solutions (Section 3.1), and then, assess users' perceptions of pros and cons of residential and community energy storage solutions (Section 3.2). We then look at consumer interest in the energy services necessary for realizing community solutions (Section 3.3). Finally, we discuss the results (Chapter 4) and draw some conclusions (Chapter 5).

\section{Materials and Methods}

We used a mixed-method approach that combined field research from two neighborhoods with five focus group discussions and an online survey of owners of a PV system. All research was conducted in Germany.

\subsection{Neighborhoods}

We studied two exemplary residential neighborhood developments, chosen because of their contrasts in terms of PV ownership and CES participation. The first, a recent development located in Groß-Umstadt in Hessen, Germany, comprises 82 properties for 90-100 residential units (mostly single- and two-family houses and a few apartment buildings). The total area of the neighborhood is $43,000 \mathrm{~m}^{2}$. The neighborhood development plan stipulates that each house must have a PV system with a minimum installed capacity of $5 \mathrm{kWp}$. Furthermore, each household must have the capability of storing energy. Residents can choose to connect to a CES system installed by ENTEGA or invest in a private residential storage solution. Entega is a municipally owned utility offering electricity, gas, water, district heating, and energy services with about 570,000 energy customers [43,44]. The CES system has a gross capacity of $115 \mathrm{kWh}$ and a charging capacity of $250 \mathrm{~kW}$. All residential units in Groß-Umstadt, as well as the CES system, are connected to the public utility grid. In 2019, 25 households were connected to the CES system.

The second neighborhood is a condominium development in Cologne, Germany. It comprises nine apartment buildings, with approx. 170 inhabitants living in 74 residential units. The total area of the neighborhood is $11,236 \mathrm{~m}^{2}$. The development is organized as a homeowners' association, with members owning their own apartments and co-owning common property. The association documents provide for a community energy concept; association members automatically become members of the energy community as well. The homeowners' association has a shared PV system with a nominal capacity of $225 \mathrm{kWp}$, as well as a CES system with a gross capacity of $96 \mathrm{kWh}$ and a charging capacity of $18 \mathrm{~kW}$, and heat pumps. The CES system and the residential units in the development constitute an internal microgrid, i.e., the CES system is not connected to the public utility grid. 


\subsection{Research Methods}

We conducted empirical research in the two neighborhoods as well as on a general level, allowing us to compare attitudes and perceptions between users already familiar with CES and those without prior experience. The following formats were used to research consumer attitudes toward CES.

In the two sample neighborhoods, we conducted a written survey of the residents in early 2018 to investigate their attitudes regarding the energy transition, as well as their specific requirements from energy storage services. In October 2018, possible energy services for community energy storage were discussed with inhabitants of the two sample neighborhoods during two user innovation workshops. In these workshops, energy storage users discussed their expectations with respect to CES, their preferences for residential versus community energy storage (Groß-Umstadt only), their views on taking over the energy storage when the funding ends (Cologne) and their perceptions and ideas regarding ancillary services. The workshops were documented, and we relied on the recorded minutes for our analyses.

At roughly the same time, in September 2018, we conducted an online survey of owners and users of PV systems in Germany. The survey aimed at identifying attitudes towards CES, conditions for its acceptance and interest in ancillary services. The invitation to participate in the survey was distributed by co2online to its newsletter subscribers and to contacts in its consumer database. Co2online is as a non-profit consulting company that supports private households in conserving energy and reducing $\mathrm{CO}_{2}$ emissions. Since all participant contacts were through co2online, we assume their interest in renewable energies to be above average. A total of 474 individuals participated in the survey, of which 94.5 percent were PV system owners. The online survey included 33 questions concerning: (1) the use of energy storage and corresponding motives, (2) preferred forms of use of energy storage, (3) attitudes toward and requirements for CES, (4) energy storage services and preferred operators of CES, and (5) sociodemographic data. We conducted descriptive statistical analyses (e.g., T-tests). For analyzing ranking questions, we calculated the average rank for each answer choice following Equation (1).

$$
\text { Average rank }=\frac{x_{1} w_{1}+x_{2} w_{2}+\cdots+x_{n} w_{n}}{\text { Total response count }}
$$

$w=$ weight of ranked position

$x=$ response count for answer choice.

Weights are assigned in reverse i.e., the respondents' most preferred choice (ranked No. 1) receives the highest weight, and their least preferred choice (ranked in the last position) receives a weight of 1 . This means that for a question with eight answers, the most preferred choice receives a weight of 8 .

In November 2018, we held two focus group discussions with PV system owners, one in Berlin and one in Dusseldorf, in order to gain insights into their attitudes towards CES. The participants, likewise recruited via co2online, discussed: (1) their general attitudes towards community energy storage vs. residential storage, (2) appropriate operating models, and (3) possible ancillary services.

In addition, we conducted a second round of three focus group discussions, in November 2019, to discuss: (1) pros and cons of energy storage in general, (2) information relied on when making investment decisions regarding energy storage, (3) attitudes towards CES vs. residential storage, and (4) possible energy services with a focus on flexible shares of CES. The focus groups took place in Hamburg, Berlin, and Munich, with participants recruited by a market research institute. The focus group discussions were recorded and transcribed. We developed a coding system and conducted a content analysis using MaxQDA.

Table 1 gives an overview of the various sample characteristics. 
Table 1. Sample characteristics.

\begin{tabular}{|c|c|c|}
\hline Method & Attribute & Characteristics \\
\hline \multirow{4}{*}{ Online survey } & Number of participants & $\mathrm{N}=474$ \\
\hline & Gender & $91 \%$ male, $6 \%$ female, $3 \%$ not stated \\
\hline & Experience with PV and energy storage & $\begin{array}{c}95 \% \text { PV system owners; } 25 \% \text { rely on or have access to an energy } \\
\text { storage system }\end{array}$ \\
\hline & Living situation & $\begin{array}{l}98 \% \text { homeowners } \\
\text { (about two-thirds single-family dwellings, one-fifth two-family, and a } \\
\text { small share of apartments); } 1 \% \text { tenants }\end{array}$ \\
\hline \multirow{4}{*}{ Focus groups } & Number of participants & $\begin{array}{l}\text { 2018: Berlin, } \mathrm{N}=9 \text {; Dusseldorf, } \mathrm{N}=7 \\
\text { 2019: Berlin, } \mathrm{N}=8 ; \text { Hamburg, } \mathrm{N}=12 ; \text { Munich } \mathrm{N}=9\end{array}$ \\
\hline & Gender & $\begin{array}{c}\text { 2018: Berlin, } 6 \text { male, } 3 \text { female; Dusseldorf, } 7 \text { male, } 0 \text { female; } \\
\text { 2019: Berlin, } 5 \text { male, } 3 \text { female; Hamburg, } 7 \text { male, } 5 \text { female; Munich, } \\
\\
7 \text { male, } 2 \text { female }\end{array}$ \\
\hline & Experience with PV and energy storage & $\begin{array}{l}\text { All participants were PV system owners; some were also storage users: } \\
\text { 2018: Berlin: 3; Dusseldorf: 1; } \\
\text { 2019: Berlin: 5; Hamburg: 9; Munich: 7; in Munich and Hamburg some } \\
\text { were joint owners of a storage system together with others in their } \\
\text { house (Hamburg 2019: 7; Munich 2019: 3). }\end{array}$ \\
\hline & Living situation & Homeowners (house or apartment) \\
\hline \multirow{4}{*}{$\begin{array}{l}\text { Questionnaires } \\
\text { (neighborhoods) }\end{array}$} & Number of participants & Groß-Umstadt: $\mathrm{N}=18$, Cologne: $\mathrm{N}=35$ \\
\hline & Gender & $\begin{array}{l}\text { Groß-Umstadt: } 11 \text { male, } 5 \text { female, } 2 \text { not stated } \\
\text { Cologne: not collected }\end{array}$ \\
\hline & Experience with PV and energy storage & $\begin{array}{l}\text { Groß-Umstadt: PV system owners; CES users }(\mathrm{N}=11) \\
\text { Cologne: users of community energy system including CES }\end{array}$ \\
\hline & Living situation & Homeowners (Groß-Umstadt: house, Cologne: apartment) \\
\hline \multirow{4}{*}{$\begin{array}{l}\text { User innovation workshops } \\
\text { (neighborhoods) }\end{array}$} & Number of participants & Groß-Umstadt: $\mathrm{N}=20$ (from 14 households), Cologne: $\mathrm{N}=15$ \\
\hline & Gender & Groß-Umstadt: 14 male, 6 female, Cologne: 8 male, 7 female \\
\hline & Experience with PV and energy storage & $\begin{array}{c}\text { Groß-Umstadt: PV system owners, CES users } \\
\text { Cologne: users of community energy system including CES }\end{array}$ \\
\hline & Living situation & Owners (Groß-Umstadt: house, Cologne: apartments) \\
\hline
\end{tabular}

As shown in the table, the samples show specific characteristics. In almost all methods, the share of male respondents was much higher. In the focus groups and the innovation workshops, we strove to attain an equal share of female respondents, but without success. Since the use of a PV system was a selection criterion, it is not surprising that almost all of the respondents-regardless of survey method-were home (or apartment) owners.

\section{Results-What Do Users Expect from Energy Storage?}

\subsection{Interest in Energy Storage and Motivation for Investing in Them}

PV system users also expressed a substantial interest in energy storage systems: In the online survey, 87.4 percent of the respondents without their own energy storage system expressed an interest in investing in such a system. The online survey included a ranking question on the motive for having bought (respondents with storage) or being interested in an energy storage system (respondents without storage) (see Table 2). In both groups, the most important motive clearly is increased self-consumption. For those respondents already using an energy storage system, this was followed by contributing to climate protection (ranked second) and independence from the electricity supplier (third); for those respondents not using energy storage, the ranking of these two motives was reversed. However, in both cases, the values of the average rank for both motives was close to each other. For those respondents already using an energy storage system, this was followed by the desire to reduce the burden of rising energy prices (fourth), and increasing the use of renewable energies (fifth); for those respondents not using energy storage, the ranking of these two reasons was reversed. Finally, the desire to use an innovative product or to increase property value as motives for investment were ranked sixth and seventh respectively by both groups and have been notably ranked lower. 
Table 2. Ranking of motives for storage acquisition.

\begin{tabular}{|c|c|c|c|c|}
\hline \multirow[t]{2}{*}{ Motive } & \multicolumn{2}{|c|}{$\begin{array}{l}\text { Respondents without Storage System } \\
\qquad(\mathrm{N}=276)\end{array}$} & \multicolumn{2}{|c|}{$\begin{array}{l}\text { Respondents with Storage System } \\
\qquad(\mathrm{N}=111)\end{array}$} \\
\hline & Average Rank & Position & Average Rank & Position \\
\hline I can increase self-consumption of renewable energy. & 5.802 & 1 & 6.275 & 1 \\
\hline I contribute to climate protection. & 4.243 & 2 & 4.091 & 3 \\
\hline I want to become more independent from the electricity supplier. & 4.234 & 3 & 4.149 & 2 \\
\hline I can reduce the burden of rising energy prices. & 3.901 & 4 & 3.268 & 5 \\
\hline I increase the use of renewable energies. & 3.856 & 5 & 3.975 & 4 \\
\hline I use an innovative product & 2.243 & 6 & 1.663 & 6 \\
\hline The storage system increases my property value. & 1.613 & 7 & 1.496 & 7 \\
\hline Other & 0.306 & 8 & 0.417 & 8 \\
\hline
\end{tabular}

Most respondents in the online survey were concerned that such investments will not pay off. They consider the financial risks of an energy storage system to be serious (64 percent indicated the risk to be very significant or significant). This was followed by ecological risks (use of critical/scarce resources, $61 \%)$, limited recycling $(55 \%)$, and environmental stress related to production $(46 \%)$. Respondents currently without access to an energy storage system ranked all risks significantly higher $(p<0.001$, T-test).

In the focus groups and the workshops in the neighborhoods, participants were interested in energy storage and some were willing to make the investment. During discussions about motives for investing in an energy storage system, one important aspect was cost savings. In this context, respondents considered increased self-consumption to be a means to reduce costs and-to a lesser extent- to become less dependent on energy suppliers. Although respondents mentioned different motives during discussion, the rankings from both the focus groups and the workshops show that, in the end, a profitable investment is more important than other aspects, e.g.:

"As I said, it depends. As soon as energy storage becomes cheaper, I'll be able to increase my own [self-] consumption and reduce expenses. But currently such storage systems are simply too expensive."

(Munich 2019-M2, I-105).

In light of the fact that private energy storage systems to date have not been financially viable [39], the question arises as to why some people nevertheless invest in energy storage. The results of the 2019 focus groups showed that participants simply did not consider all relevant parameters influencing the cost of storage operation-e.g., cycle life, efficiency, and depth-of-charge characteristics-when purchasing their storage system. Only a few participants knew the cost of their storage system. Additionally, no one was able estimate the specific costs per kWh of their own energy storage system. The 2019 focus groups also revealed that those participants who had invested in an energy storage system did not monitor cost reductions after installation.

In the 2019 focus groups, we additionally inquired as to how participants with energy storage had arrived at their decision to buy and the information they had relied upon for their decision. Most drew upon a combination of information sources, such as information from the Internet, an energy utility, installers, or even neighbors and friends.

"In our street some already had [a storage system], so we started talking about it [ ... ], and they named some companies. I did some Internet research [ ... ] and then I contacted several companies."

(Hamburg 2019-HH9, I-82).

Most had requested bids from one or more installation firms or an energy utility and made their decision after considering factors such as cost, their impression of reliability of the offer, and their own trust in the seller's competence. Moreover, the perceived quality of the seller's guidance was important. 
"The [companies] consulted us and then we decided. [ ... ] We bought [from the firm] where the consultation was better and [the assumptions being made] seemed more plausible."

(Hamburg 2019—HH9, I-82).

However, several participants were not satisfied with the advice they received. Due to a lack of knowledge, they felt overly dependent on the providers.

“Well, there were some surprises. It was not very nice because they simply hadn't thought it through and we of course didn't have the necessary knowledge."

(Berlin 2019-B7, I-97).

Some participants perceived a need for better information regarding energy storage.

"Well, it would be nice if someone provided real information and advice instead of only providing a sales quote because I don't really have a clue."

(Munich 2019-M3, I-108).

\subsection{Comparison of Storage Systems and Requirements Concerning Community Storage}

Respondents in the online survey showed a clear preference for residential energy storage (see Figure 2): about two-thirds (64\%) preferred to own and six percent to rent a residential energy storage system. About half of those who preferred their own residential storage system suggested that with a residential storage system, they would be more independent and have better control over the storage system. Moreover, about 15\% feared that a CES causes bureaucracy and coordination with neighbors, and about 13 percent stressed that they were the only residents with a PV system in their neighborhood.

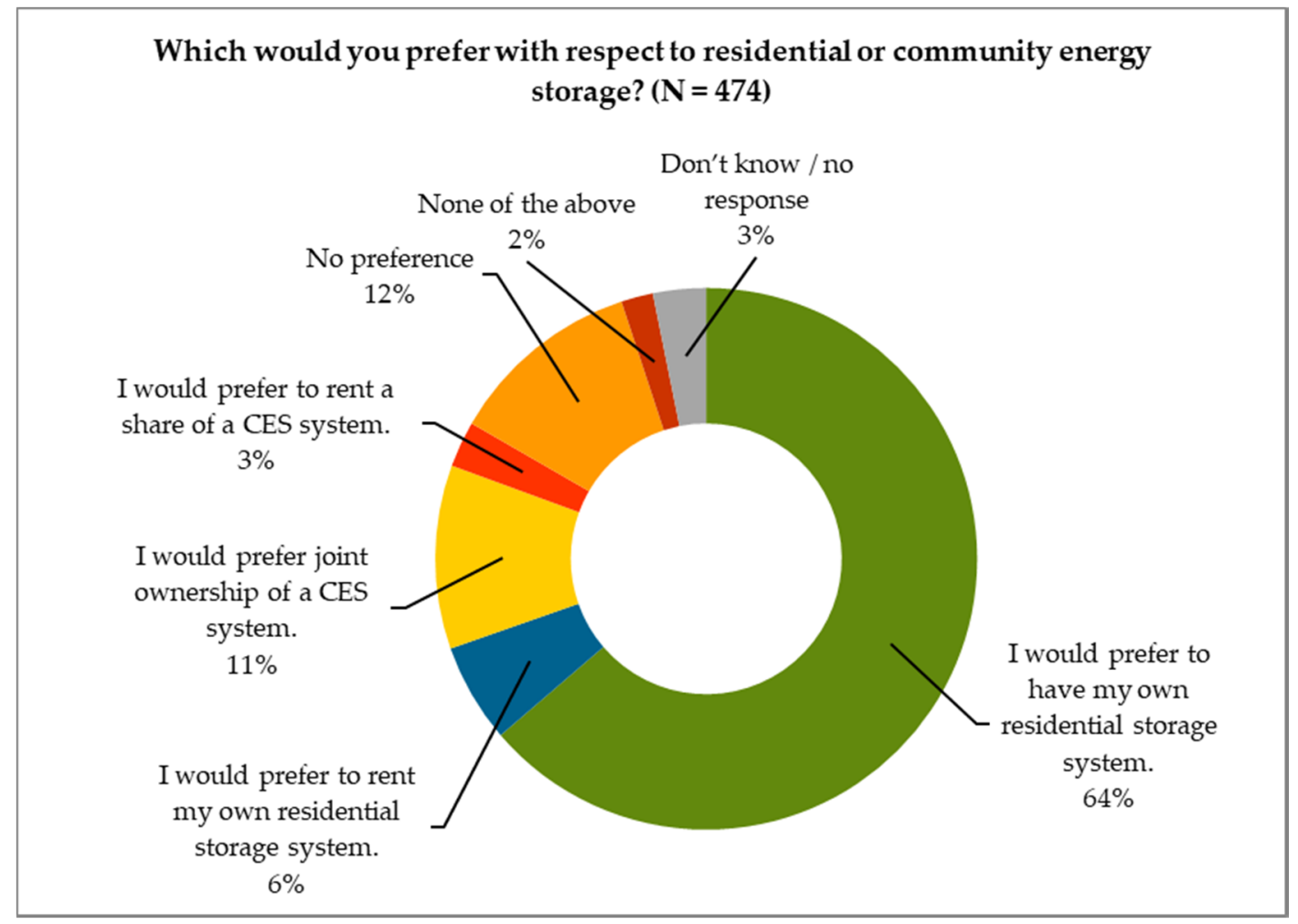

Figure 2. Preferred type of storage usage.

Only 14 percent preferred CES, with 11 percent preferring joint ownership with other residents and three percent rental participation. Those respondents who were in favor of community solutions 
mainly argued that these are more cost-efficient and require less or no personal investment and achieve better capacity utilization. A few also noted that one large storage system rather than several smaller ones is more resource-efficient. Those who prefer renting stressed the lack of a need for personal investment and professionally managed operation and maintenance.

We asked whether the respondents could imagine participating in CES if it was offered to them. There was a substantial receptiveness to CES, we found, with 64 percent agreeing with such a proposition and only 22 percent disagreeing (see Figure 3). This result shows a general openness towards CES. However, it is not possible to deduce from the stated willingness to act whether the respondents would actually take part. In the following, we will go into more detail about what respondents think about advantages and disadvantages of CES and factors influencing the decision for CES.

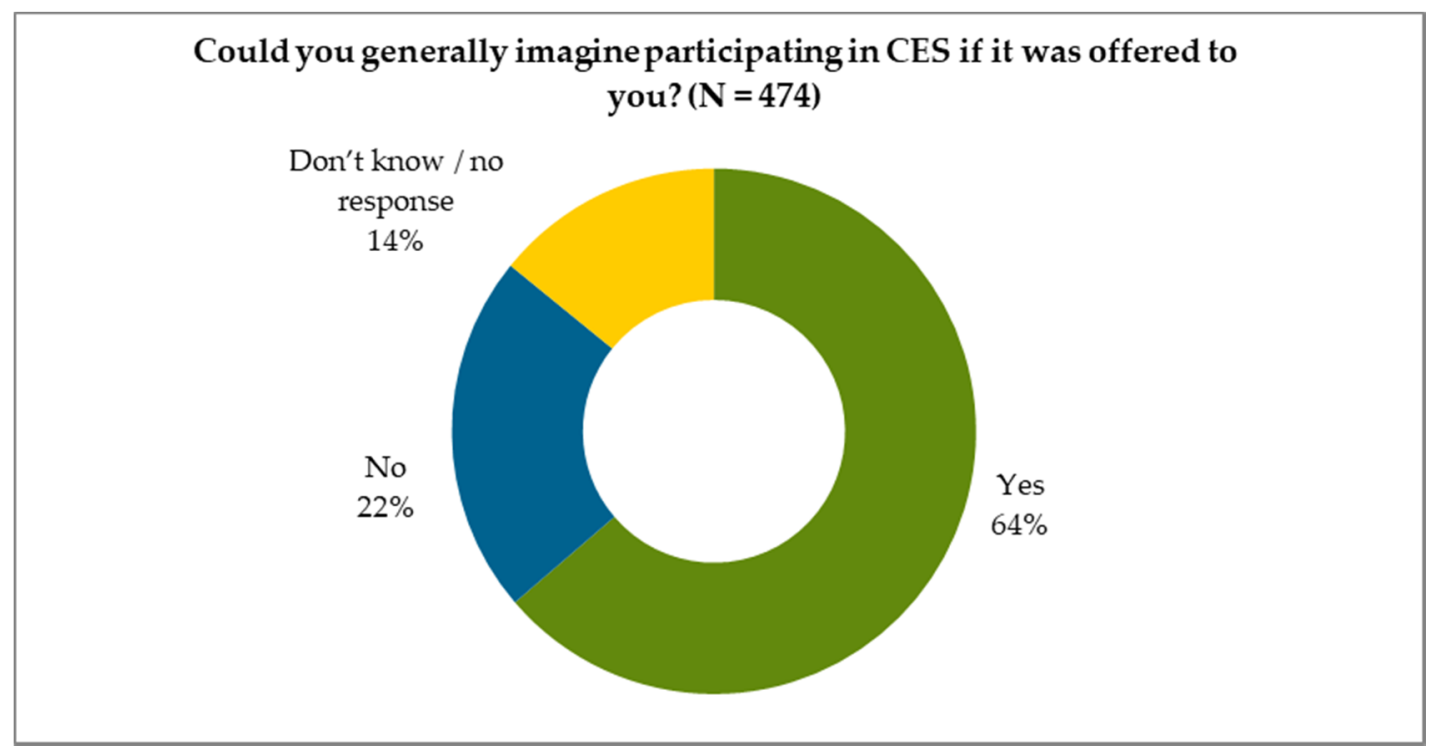

Figure 3. Assessment of willingness to participate in a CES project.

Our other investigations also showed significant receptivity to and interest in CES. In the focus groups, we asked participants whether they would prefer a residential or a community storage system, provided that community storage was not more expensive. The majority of participants chose CES, and most preferred share rental of a CES over owning.

The surveys in the two neighborhoods we studied showed differences: The development in Cologne has a community energy concept that integrates a PV system, energy storage and heat pumps; thus, it is not possible for residents to operate an individual energy storage system. Here, all participants were accordingly in favor of community storage. In Groß-Umstadt, where residents not currently participating in CES also responded, the interest in residential energy storage was almost as high as that for community storage. However, only seven households not participating in the CES project participated in the survey and the high approval rate cannot be transferred to the majority who did not participate. In the innovation workshop in Groß-Umstadt, where only participants of the CES project took part, almost all were in favor of CES.

In all of the surveys, we analyzed respondents' perceptions of the advantages and disadvantages of CES versus residential storage. Although most participants in the online survey preferred residential energy storage, many did perceive certain advantages of CES (see Figure 4). They assumed that a CES can better balance power fluctuations in the grid, and thereby, increase net stability; there was also the assumption that CES is more cost-effective than residential storage. Still, respondents also perceived disadvantages. Many were concerned that CES requires too much coordination with neighbors, and that such common property acquisitions are generally treated less carefully by users. Slightly less than a third assumed that with CES there would be an increased data privacy risk. Other arguments for CES were less relevant, e.g., more respondents disagreed than agreed with 
the potential for increased fire risk with residential storage, or the idea that acquisition and operation should be left to a third party.

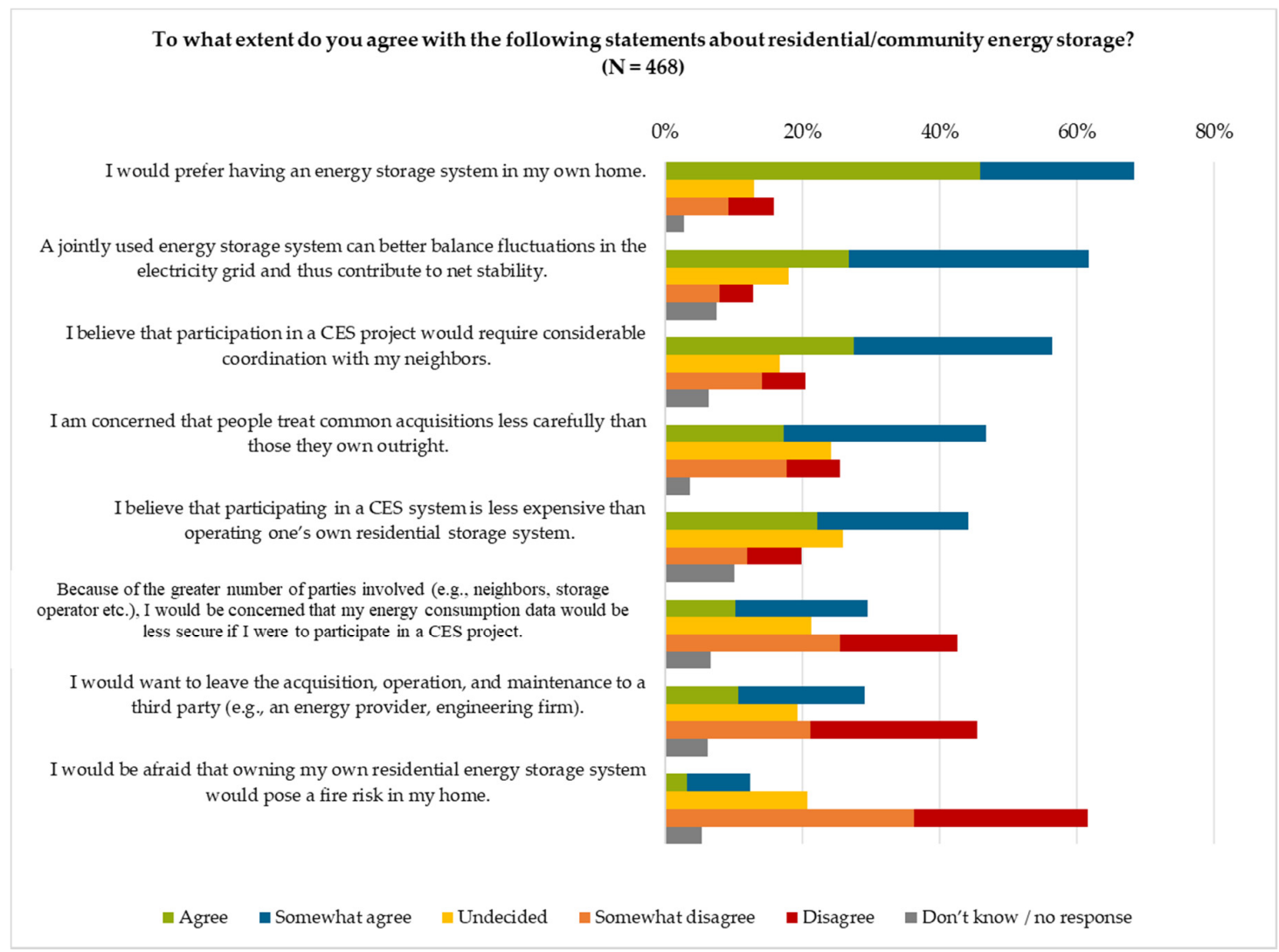

Figure 4. Assessment of (community) energy storage.

A comparison of those with a preference for community or residential energy storage shows that those respondents who prefer CES agree significantly more on the advantages of community storage and significantly less on the disadvantages (T-test, $p<0.001$ ). However, differences are not significant for the fear of fire risk. A comparison between respondents who already own an energy storage system and those who do not shows almost no significant differences. Respondents owning an energy storage system, nevertheless, showed significantly less agreement on the fear of fire risk (T-test, $p<0.001$ ) and data security (T-test, $p<0.05$ ).

In the online survey, we asked under which conditions the respondents would be interested in participating in a CES system (ranking question, see Table 3). By far, the most important condition was that the rental fee for such storage be less than the reduction in electricity costs attained using the storage system. The next important condition was that respondents could freely choose their electricity provider, the third that the storage operator would ensure a higher proportion of renewable energies in the neighborhood, and the fourth that the storage operator uses the storage systems for grid relief. Ranked last were the stipulations that the storage is offered in combination with energy consulting and that the storage contract could be cancelled upon relatively short notice. This shows that once again costs are an important factor; however, respondents are open to other arguments. 
Table 3. Conditions for being interested in participating in a CES system ( $N=332)$.

\begin{tabular}{llc}
\hline \multicolumn{1}{c}{ Conditions } & Average Rank & Position \\
\hline $\begin{array}{l}\text { Rental fee for CES should be less than the reduction in electricity cost attained using } \\
\text { the CES system. }\end{array}$ & 5.777 & 1 \\
\hline Users can freely choose their electricity provider. & 3.452 & 2 \\
\hline $\begin{array}{l}\text { Storage operator should ensure higher proportion or renewable energies } \\
\text { in the neighborhood. }\end{array}$ & 3.130 & 3 \\
\hline Storage operator should use the storage system for grid relief. & 2.729 & 4 \\
\hline The storage is offered in combination with energy consulting. & 2.277 & 5 \\
\hline The storage contract could be cancelled upon short notice. & 1.967 & 6 \\
\hline Other & 0.497 & 7 \\
\hline
\end{tabular}

In the surveys in the two neighborhoods, the view of the advantages of CES was quite similar to the online survey; however, an even larger share of respondents assumed that CES is more cost-efficient. The residents were somewhat less in agreement about the disadvantages. Participants in the focus groups, in particular, expected economic advantages and assumed that larger solutions would have lower specific costs and can be offered at a better price.

"I think community energy storage is a great thing and if there was a system in my district I would participate. My requirement is that it has to be cheaper. The price is the kicker."

(Berlin 2019-B5, III-61).

Focus group participants moreover assumed that CES is more efficient and more reliable and can better be used to provide grid relief. Their arguments for renting were that professional staff would take care of operation and maintenance, and that they would bear less of the investment cost and financial risk:

"With community energy storage I would in effect be safe from failure. When the storage system breaks down [ ... ], it's not my problem."

(Dusseldorf 2018-D3, I-105).

"It's simply more reliable [ ... ] and also better maintained."

(Dusseldorf 2018-D1, I-144).

Moreover, some participants appreciated that less knowledge and effort on their part is necessary. They assumed that CES is a good option for those who have less knowledge about or interest in technical details, but who still want to participate in the energy transition.

"If it's not more expensive I would choose community energy storage because then I don't have any work with it."

(Munich 2019-M6, III-77).

“[ ... ] Whenever we purchase something that we don't understand, we either have to acquire knowledge, or we have to find someone who explains it to us and that can be very time-consuming. Therefore, in terms of the required expertise community energy storage would be an advantage for me."

(Berlin 2018-B2, I-62).

A few participants in the focus groups mentioned that CES may increase the sense of community in the neighborhood, and additionally, is a visible sign that a district is engaged in supporting the energy system transition: 
"Community energy storage also brings a kind of community spirit: together we are doing something for the environment. Those are the factors that are important to develop acceptance [of the energy transition]."

(Dusseldorf 2018-D5, I-219).

Many focus group participants, however, doubted that a community storage system could be realized in their neighborhood; they assumed that there are not enough PV systems. Their main concern regarding CES was whether equal and fair billing could be realized. They expressed a concern that others would use the renewable electricity they produced while they were left to buy "expensive electricity" from the energy utility:

"The most important thing would be that there is an equitable distribution. If I constantly feed in [electricity] and others only withdraw, this has to be recorded and compensated in terms of costs."

(Hamburg 2019-HH1, II-21).

Some participants moreover stressed that a CES system would reduce their PV-based independence from external suppliers:

"With such a large [storage] system, one again becomes dependent on some kind of operator."

(Munich 2019-M2, II-76).

In the 2018 focus groups, in which many participants had a strong technical interest in renewable energies, some participants were more in favor of residential storage, which, they argued, offered better control and greater freedom in making decisions. One participant was moreover critical because he feared that CES users would feel less responsible with respect to energy consumption and environmental protection.

"Regarding community energy storage, I would be afraid that we all would once again say: 'Electricity comes from the electrical outlet.' And this educational effect—of being the master of my own technology and power consumption-would be lost."

(Dusseldorf 2018-D5, I-161).

In the user innovation workshop in Groß-Umstadt, participants were clearly in favor of CES and system rental. Their arguments resemble those of the focus groups: They would be less engaged with the storage system (e.g., technical aspects, current developments); professional staff would take care of maintenance and repair and catch problems sooner rather than later. They assume that CES is more cost-effective than residential storage. Moreover, many participants do not have the physical space needed to install their own residential storage system, and some see an advantage in not having the additional fire load in their home. Participants in the innovation workshops did not mention the fear of unequal billing and use of the CES system, which was very prominent in the focus groups. In the user innovation workshop in Cologne participants did not discuss the question, whether they prefer a community or residential storage system as the residents in the Cologne neighborhood fall under a community energy concept.

The question of who is operating the CES system also influences its acceptance (see Figure 5). Respondents to the online survey clearly trust in local and regional energy utilities (more than 80 percent showed great or medium trust). More than two-thirds of the respondents also trust in so-called energy communities and municipalities. The trust in national energy utilities and housing companies is notably lower, with almost half of the respondents indicating little or no trust in housing companies. In terms of trust, we can observe group differences between storage system owners and non-owners, as well as between people who prefer residential storage and those who prefer community storage. Those who 
prefer CES, in particular, have more confidence in energy cooperatives $(p<0.001)$. Those who prefer residential storage are generally more skeptical $(p<0.01)$, except for network operators and storage producers, for whom no significant differences can be found. Storage owners show higher trust $(p<0.01)$ in storage producers than non-owners and lower trust in local and regional energy utilities $(p<0.05)$.

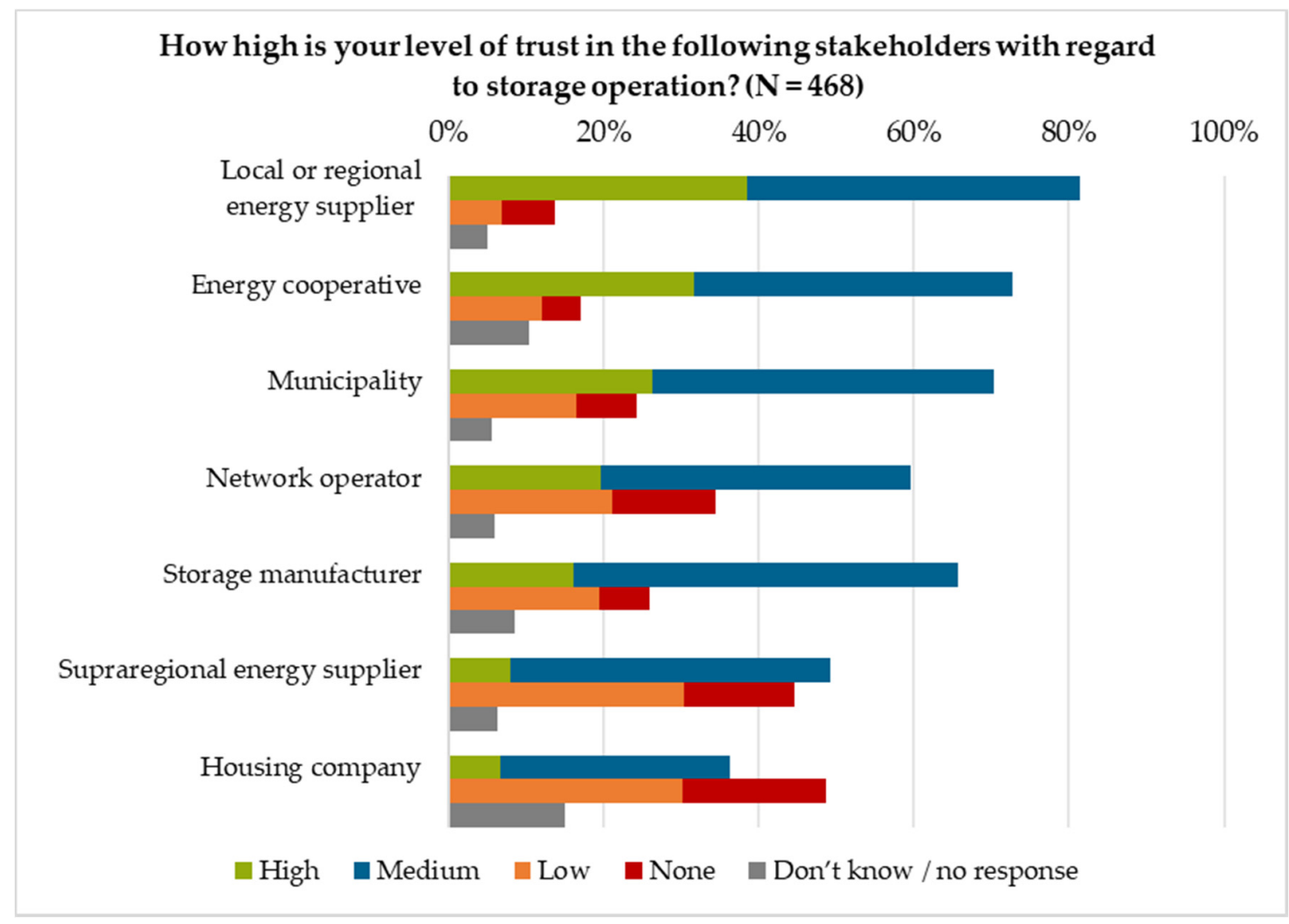

Figure 5. Trust in potential operators of an energy storage system.

Focus group participants also show strong trust in local and regional energy suppliers and energy cooperatives. They mistrust large energy suppliers and housing companies, which they assume are more likely to pursue their own economic interests and exclude customers from participation in savings.

“Housing companies would be [a possibility], but I wouldn't really trust them because, sure, they make plans and say: 'Okay, I need a 15-20 percent return on equity, everything else isn't of interest to me.'"

(Berlin 2018-B7, II-66).

"Municipal utilities that are close by and already have a relationship of trust with the customer, [... ] I believe they could do it."

(Dusseldorf 2018-D5, II-29).

Moreover, the participants in the 2019 focus groups argued for a short notice of cancellation (mainly between three and six months) and choice of electricity provider.

\subsection{Energy Storage Services}

Shared energy storage at the community level needs to be supported by ancillary services, such as renewable energy prioritization, energy flow management, and operation and maintenance. How do 
users perceive these services? Would they be willing to pay for them? The online survey shows a generally high level of interest in the energy services described in Figure 6, provided that no additional costs are incurred overall (agreement between 40 and $73 \%$ ).

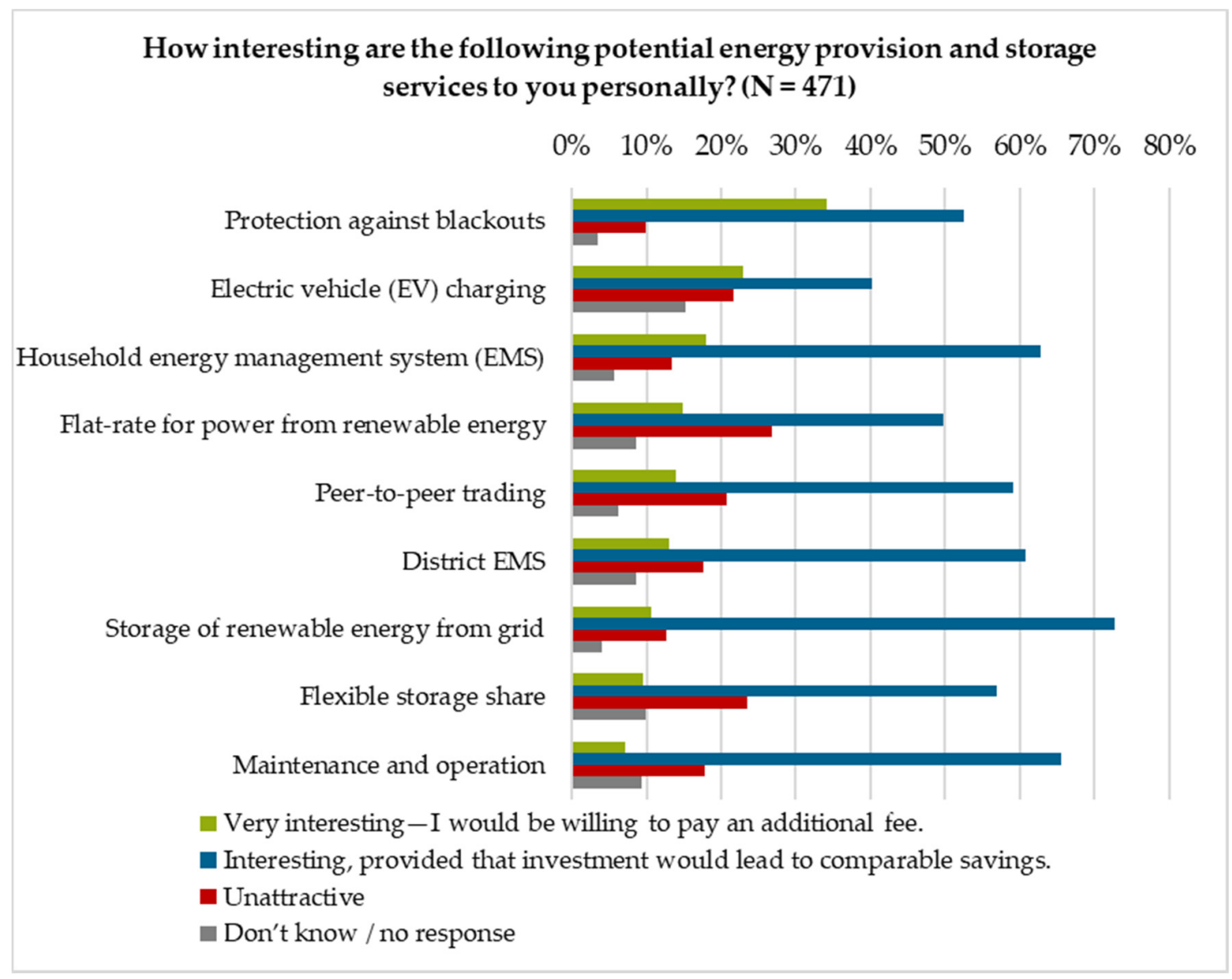

Figure 6. Assessment of various energy services.

At first glance, protection against power losses appears to be the most attractive service, despite the very low probability of blackout occurrence. In Germany, the average annual outage duration for customers served was a mere $14 \mathrm{~min}$ in 2018 [45]. In the online survey, it received the highest approval ratings in terms of willingness to pay an additional charge, with support from 34 percent of respondents, followed by the possibility of charging an electric car via the energy storage system (23\%). The willingness to pay for the charging of electric cars and energy management for the household or the neighborhood is greater among those with their own energy storage system.

In the focus groups, some participants confirmed a strong interest in protection against blackouts, while others acknowledged that the power supply in Germany is very reliable and the occurrence of blackouts is seldom.

"For me, a very important topic is protection against blackouts. [... ] That is something important and would be great."

(Dusseldorf 2018-D7, III-98).

Charging of electric vehicles was positively discussed in the workshops and focus groups, although only a few participants already drove an electric car. Participants, however, were skeptical about the future possibility of bidirectional charging because they perceive this as infringing on their own options: 
"I would not like it [ ... ] if somebody could tap the electricity from my car because I can never know exactly whether I might have to drive somewhere."

(Berlin 2019-B5, II-55)

The focus groups in 2019 showed that most participants were unfamiliar with ancillary energy services. Almost no one had dealt with such services or even load management, nor had much thought been given to the cost of the stored electricity. This was even true of those already participating in shared energy storage (HH 2019). On the other hand, within the 2018 focus groups, some participants did have experience with ancillary services such as monitoring and energy management systems. Several participants in the 2018 focus groups used smartphone apps to monitor their power generation and consumption of self-produced electricity.

Many focus group participants estimated that electricity from the grid is more expensive than from storage and were concerned about disadvantages due to unequal use of the CES system. To avoid unfair billing, the majority highlighted the need for transparent energy management as a necessary prerequisite. Many focus group participants, however, found it difficult to imagine the management of numerous households connected to a CES system. "The allocation of stored electricity to the person who wants to use it later" (Berlin 2018-B1, I-57) was estimated to be too difficult. At the same time, all respondents were interested in the services of monitoring, energy management, and storage operation.

"I really see added value in the monitoring service. Someone who professionally operates [an energy storage system] will have a great deal more experience and knowledge than someone who does this on his own."

(Dusseldorf 2018-D1, I-208).

In the two neighborhoods we studied, the residents described monitoring, management, and operation as necessary services, but they were hardly willing to pay for them. The primary goal in the Cologne neighborhood was to achieve possible cost savings by using CES to increase the rate of self-consumption. In this context, participants also desired greater information and indications on energy saving and times when the consumption of self-generated electricity is possible (e.g., by means of a visual display such as a "traffic light") as well as notification when unusual consumption rates or failures occur.

A particular advantage of CES is that the individual household can rent a flexible share of the storage according to its actual needs. Shared use of the CES system provides such flexibility. The CES operator can then apportion unused storage to other services, e.g., the control energy market. Focus group participants found the idea of variable storage shares very complex and in need of further explanation. Only after a longer discussion in the focus groups did a majority of participants agree that variable storage could bring advantages such as gains in flexibility through an only-as-needed capacity rental model-for example, easier adaptation to changes in household energy requirements-or the ability to plan costs. The participants linked the topic of flexible storage shares with a discussion of monitoring and maintenance and the rental model versus ownership. For many, it was not clear why the optimal storage size would differ during the year and why it was necessary to define an upper limit to the amount of electric power that could be stored at any one time. They also expressed the desire to store electricity (at least virtually) for a longer period of time, so that their summertime solar power could be used in winter. There was a greater receptivity in the Groß-Umstadt district, where the energy utility, ENTEGA, is planning to offer flexible storage shares as a service. The service has already been addressed in various customer events that ENTEGA has held in Groß-Umstadt, which has led to a greater understanding of the service there. Here, as in the Cologne housing development, some workshop participants relied on the use of analogies, such as comparing storage management to that of a bank account or shared network access with Netflix, in order to better understand the benefits. 


\section{Discussion}

In all of the surveys, respondents described the economic arguments as being decisive for making investment decisions with respect to energy storage. Their goal is to increase self-consumption, which is perceived as a means to lower costs and increase independence. Although investment in energy storage is still economically infeasible [11], more than 100,000 consumers in Germany have already acquired such energy storage systems [3]. Given the complexity of the investment and cost-return issues, we find that some consumers made decisions based on insufficient information or relied on idealistic payback periods provided by storage providers. Furthermore, once such an energy storage system has been acquired, many consumers do not control or monitor the cost or actual savings in the energy bill. This suggests that, although economic arguments are often presented as the most important issue, many decisions are in fact only ostensibly based on economic reasoning.

The differences regarding consumer preferences for residential versus community energy storage arising among the survey methods suggest that consumers who are better informed about CES are more inclined to this sharing model. This was especially obvious in the two housing developments we surveyed, where residents had acquired real world experience with CES and were supported and supplied with information by the local storage operator.

Soland et al. [15] identified safety and ecological concerns as well as economic reasons as arguments for preferring CES. We can confirm these results regarding economic motives and partly regarding safety concerns. In our surveys, the ecological advantages of CES, however, were scarcely mentioned. With respect to economic arguments, consumers assumed that CES is more efficient and cost-effective due to economies of scale. We moreover find that consumers prefer CES because it is operated by professional staff, and hence, more reliable, which minimizes the level of knowledge and effort required from the consumer. Moreover, consumers appreciate the role of CES in providing grid support functions.

Consumers who are skeptical about CES fear that the distribution of cost will not be fair among participants-this was also found by Ambrosio-Albalá et al. [14]. Moreover, they perceive disadvantages such as increased coordination with neighbors, increased data security risks or fear that other participants treat common acquisitions less carefully. Abating these perceived disadvantages can help to increase the acceptance of CES.

In addition, there is a group of technically skilled and interested consumers who prefer to have their own storage systems in order to keep their technical devices and their energy flows under control. CES operators will have difficulties to reach this group and will only be able to convince them if they offer technically innovative solutions and attractive ancillary services such as monitoring and detailed evaluation of electricity production and consumption data.

The results of our online survey confirm Kalkbrenner's [16] findings that consumers prefer ownership over use-rights, however the focus groups and our research in Groß-Umstadt and Cologne paint a different picture. We must assume that consumers who are more familiar with and more knowledgeable about CES and the various ownership models are also open to renting. Here again, the advantages in handing off investment costs, responsibility, and risk are the dominant arguments.

CES requires ancillary energy services in order to function. In contrast to a residential storage system, the participants' energy flows into and out of the community storage must be monitored in order to provide the transparency required for billing and to ensure optimal storage operation. This topic was new for most of the participants in our inquiries and needed further explanation during discussions. Accordingly, the results of the online survey must be seen primarily as an expression of interest in such services, provided that they are not economically disadvantageous. However, it is hardly possible to deduce which of these services participants might be interested in and willing to pay for. The expressed greater willingness to pay for emergency power and e-mobility is for specific services whose direct benefits are more easily recognizable. Overall, the concern about power failures seems to be a strong incentive in the trade-off between CES and residential energy storage, even though such blackouts occur very seldom in Germany. Feedback from the two neighborhoods underlines 
that residents can better discuss and make decisions about storage services after they have dealt with the subject in depth. Such energy services must be explained in some detail, as the benefits of CES will only become readily apparent to consumers when they are sufficiently well informed. Comparisons of results, however, suggest that an informed discussion of ancillary energy services and energy storage is difficult to achieve if the services are not a part of an overall energy concept. People can better discuss these services when they are familiar with and understand the context in which they are to be applied. Even though it was possible to briefly outline such services in the focus groups, in-depth discussion was only possible in the two neighborhoods we surveyed.

The participants in our surveys were all owners and/or users of a PV system. These results can, thus, not be transferred to consumers not using PV. Given, however, that PV system owners are the relevant target group for CES, our results can still be considered relevant. The majority of respondents were male, and many were technically skilled or interested in the technical aspects. Further research into female consumers and those with more limited technical knowledge is necessary to gain broader insights. Our research analyzed interest in ancillary energy services for CES based on hypothetical offerings. A better insight into consumer acceptance, interest and willingness to pay would be possible if real world proposals were studied. Real world user experience with CES is still limited; here, further research is needed to compare user views and perceptions in various neighborhoods or pilot projects. The neighborhoods we studied were recent housing developments and most participants in our research were single-family or condominium owners. The questions of how to introduce CES into already developed areas and how to involve residents-owners as well as tenants-have to be studied in more detail. This study focused on Germany. Since CES is currently still in the pilot project phase, our results may be relevant for other countries as well. However, the question of who should operate CES has to be answered considering the national context, i.e., the historical development of energy supply and grid management. A transnational comparison of users' views on CES, however, would offer deeper insights into influential factors, such as laws and regulations at the national level, cultural identity, or the like.

\section{Conclusions}

Among users of PV systems, there exists a significant interest in energy storage systems and they perceive many advantages related to these. Although about six percent of the 1.7 million PV owners in Germany have already installed an energy storage system [3], acceptance among the remainder is rather more passive than active. This is due to barriers such as limited economic feasibility, the complexity of the topic, and lack of trust in information sources.

The provision of information and advice on energy storage makes for better decision-making. It is safe to assume that better consulting and advisory services will lead to a greater degree of active acceptance and to investments in storage facilities being made on the basis of actual costs. It is possible that with better information, less PV users will invest in storage under current conditions. However, since economic arguments are not the only motive, it can be assumed that with better information, PV users or those interested in PV systems will still be drawn to energy storage.

Those consumers who have already acquired a residential energy storage system mainly did so to increase their self-consumption; others were motivated by an interest in the technology. However, in order to motivate PV users with less technical interest or know-how to invest or to participate in CES, clear and economically feasible offerings are important. Currently, it is still difficult to compare the energy costs of PV systems combined with energy storage and many consumers are overwhelmed in the search for reliable information.

PV owners show limited interest in CES, but their interest increases when they are better informed. They need information on the comparison between residential and community energy storage regarding cost, efficiency and environmental aspects. Moreover, they need information on the operator of the CES system and on how the fair participation of different households is reached. Information on CES moreover needs to reach more PV users. There is also a need for more pilot and demonstration 
projects so that storage providers and potential customers can gain practical experience and learn about the advantages, disadvantages, and possible applications. Therefore, best-practice examples for community solutions must still be promoted and communicated. It is very unlikely that PV users would start a CES initiative on their own. Professional providers are needed to increase the use of CES. As mentioned by other authors $[5,12,13,46]$, changes in the German regulations are needed to make the implementation of CES financially feasible. To increase economic feasibility, CES should be developed as multi-use storage including various ancillary energy services, and providers should additionally aim at markets other than the consumer market [41]. In setting pricing, CES providers should keep in mind that PV users tend to compare the cost of CES to that of residential storage systems.

CES providers should moreover consider the perceived disadvantages we identified: It is important to communicate how a fair and transparent billing will be reached, and how data security is guaranteed. Moreover, they should clarify that professional staff takes care of the CES system and that there is no need to coordinate with neighbors and no risk that other users damage the CES system through careless treatment.

In order to convince the group of technology enthusiasts, a professional storage operator should offer more in-depth analyses, e.g., the provision of monitoring data for the respective household, a forecast of storage performance for the next week, month or year, or make suggestions for increasing self-consumption.

One question that we have only dealt with in passing is the organizational structure for CES operation. Who should initiate CES projects? The advantages of CES can best be exploited if central monitoring and energy management systems are established. The Cologne example shows that the integration of CES into a comprehensive energy concept brings further advantages due to the combination of technologies, i.e., heat pumps and thermal storage. However, the preparation of such a centralized energy management protocol requires advanced energy planning and management qualifications. In particular, it requires specialization in the field of energy data analysis and management, which can best be realized by a professional operator. Currently, CES operators are still acquiring experience with the viable operation of CES and related energy services in pilot projects.

Local municipalities can create supportive conditions for participation in CES: in the sample neighborhood in Groß-Umstadt, the neighborhood development plan stipulated the installation of PV systems and the use of storage systems. This prescription increased the residents' interest in CES.

Even if environmental protection and support for the energy transition are not the first priorities of consumers with an interest in energy storage, the perception of doing something good for the environment or helping with climate protection can increase the willingness to invest in energy storage. Here, CES has the advantage due to lower resource needs and more options for flexibility, and these advantages should be emphasized more strongly to increase interest in and acceptance of CES. CES can provide grid services or store electricity from the grid and can, thus, contribute to net stabilization. These are benefits that are also appreciated by PV owners and will help to increase acceptance.

Author Contributions: Conceptualization, F.M. and E.H.; methodology, E.H. and F.M.; formal analysis of online survey data, E.H.; analysis of focus groups and data from the neighborhoods, E.H. and F.M.; writing-original draft preparation, F.M. and E.H.; writing-review and editing, E.H. and F.M.; visualization, E.H. and F.M.; supervision F.M. and E.H.; project administration, F.M. and E.H.; funding acquisition, F.M. and E.H. All authors have read and agreed to the published version of the manuscript.

Funding: This research was funded by the German Federal Ministry of Education and Research (Bundesministerium für Bildung und Forschung, 02K15A020). Further project results can be found at www.esquire-projekt.de.

Acknowledgments: We are grateful to our colleagues Swantje Gährs (as leader of the ESQUIRE project) and Jan Knoefel for discussing our research results. We moreover thank our project partners ENTEGA and evohaus for the opportunity to conduct empirical research in the two sample neighborhoods. We thank co2online for the realization of the online survey and for support in data analysis. We are moreover grateful to our student workers Paula Wörteler, Meike Ortmanns, and Ruth Berkowitz, who supported the project through literature research, data analysis, drafting of text passages, and drafting of visualizations. 
Conflicts of Interest: The authors declare no conflict of interest. The funders had no role in the design of the study; in the collection, analyses, or interpretation of data; in the writing of the manuscript; or in the decision to publish the results.

\section{References}

1. Agnew, S.; Dargusch, P. Effect of residential solar and storage on centralized electricity supply systems. Nat. Clim. Chang. 2015, 5. [CrossRef]

2. Kairies, K.-P.; Magnor, D.; Sauer, D.U. Scientific Measuring and Evaluation Program for Photovoltaic Battery Systems (WMEP PV-Speicher). Energy Procedia 2015, 73, 200-207. [CrossRef]

3. Wirth, H.; Schneider, K. Aktuelle Fakten zur Photovoltaik in Deutschland; Fraunhofer ISE: Freiburg, Germany, 2020.

4. Koirala, B.P.; van Oost, E.; van der Windt, H. Community energy storage: A responsible innovation towards a sustainable energy system? Appl. Energy 2018, 231, 570-585. [CrossRef]

5. Müller, S.C.; Welpe, I.M. Sharing electricity storage at the community level: An empirical analysis of potential business models and barriers. Energy Policy 2018, 118, 492-503. [CrossRef]

6. van der Schoor, T.; Scholtens, B. Power to the people: Local community initiatives and the transition to sustainable energy. Renew. Sustain. Energy Rev. 2015, 43, 666-675. [CrossRef]

7. Brummer, V. Community energy-Benefits and barriers: A comparative literature review of community energy in the UK, Germany and the USA, the benefits it provides for society and the barriers it faces. Renew. Sustain. Energy Rev. 2018, 94, 187-196. [CrossRef]

8. Marczinkowski, H.M.; Østergaard, P.A. Residential versus communal combination of photovoltaic and battery in smart energy systems. Energy 2018, 152, 466-475. [CrossRef]

9. Koirala, B.P.; Hakvoort, R.A.; van Oost, E.C.; van der Windt, H. Community energy storage: Governance and business models. In Consumer, Prosumer, Prosumager: How Service Innovations Will Disrupt the Utility Business Model; Sioshansi, F., Ed.; Academic Press, an imprint of Elsevier: London, UK, 2019; pp. 209-234. ISBN 978-0-12-816836-3.

10. Lombardi, P.; Schwabe, F. Sharing economy as a new business model for energy storage systems. Appl. Energy 2017, 188, 485-496. [CrossRef]

11. van der Stelt, S.; AlSkaif, T.; van Sark, W. Techno-economic analysis of household and community energy storage for residential prosumers with smart appliances. Appl. Energy 2018, 209, 266-276. [CrossRef]

12. Gährs, S.; Knoefel, J. Anforderungen verschiedener Stakeholder an Dienstleistungen mit Quartierspeichern. Ergebnisse einer Analyse von Stakeholderinterviews. 2018. Available online: https://www.ioew.de/fileadmin/ user_upload/BILDER_und_Downloaddateien/Publikationen/2018/G\%C3\%A4hrs-Knoefel_Anforderungen_ verschiedener_Stakeholder_ESQUIRE_2018-09-17.pdf (accessed on 21 April 2020).

13. Gährs, S.; Knoefel, J. Stakeholder demands and regulatory framework for community energy storage with a focus on Germany. Energy Policy 2020. accepted.

14. Ambrosio-Albalá, P.; Upham, P.; Bale, C.S.E. Purely ornamental? Public perceptions of distributed energy storage in the United Kingdom. Energy Res. Soc. Sci. 2019, 48, 139-150. [CrossRef]

15. Soland, M.; Loosli, S.; Koch, J.; Christ, O. Acceptance among residential electricity consumers regarding scenarios of a transformed energy system in Switzerland-A focus group study. Energy Effic. 2018, 11, 1673-1688. [CrossRef]

16. Kalkbrenner, B.J. Residential vs. community battery storage systems-Consumer preferences in Germany. Energy Policy 2019, 129, 1355-1363. [CrossRef]

17. Kloppenburg, S.; Smale, R.; Verkade, N. Technologies of Engagement: How Battery Storage Technologies Shape Householder Participation in Energy Transitions. Energies 2019, 12, 4384. [CrossRef]

18. Gährs, S.; Hoffmann, E. Dienstleistungen mit Quartierspeichern; e|m|w: Essen, Germany, 2018; pp. 68-70.

19. Hoffmann, E.; Mohaupt, F.; Ortmanns, M. Akzeptanz von Speicherdienstleistungen und Weiteren Energiedienstleistungen. Stand der Forschung aus Sozialwissenschaftlicher Perspektive. 2018. Available online: https://www.esquire-projekt.de/data/esquire/Datein/Arbeitspapier_Akzeptanz_von_ Speicherdienstleistungen_und_weiteren_Energiedienstleistungen.pdf (accessed on 22 April 2020).

20. Wolsink, M. The research agenda on social acceptance of distributed generation in smart grids: Renewable as common pool resources. Renew. Sustain. Energy Rev. 2012, 16, 822-835. [CrossRef] 
21. Hoffmann, E. User Integration in Sustainable Product Development: Organisational Learning through Boundary-Spanning Processes; Routledge: Abingdon, UK; New York, NY, USA, 2017; ISBN 978-1-351-27792-1.

22. Broughel, A.E.; Hampl, N. Community financing of renewable energy projects in Austria and Switzerland: Profiles of potential investors. Energy Policy 2018, 123, 722-736. [CrossRef]

23. European Commission. EU Reference Scenario 2016: Energy, Transport and GHG Emissions-Trends to 2050. Main Results; European Union: Luxembourg, 2016.

24. Schäfer, M.; Keppler, D. Modelle der Technikorientierten Akzeptanzforschung. Überblick und Reflexion am Beispiel eines Forschungsprojekts zur Implementierung Innovativer Technischer Energieeffizienz-Maßnahmen; Discussion Paper; Technische Universität Berlin: Berlin, Germany, 2013.

25. Hildebrand, J.; Rau, I.; Schweizer Ries, P. Akzeptanz und Beteiligung-Ein ungleiches Paar. In Handbuch Energiewende und Partizipation; Holstenkamp, L., Radtke, J., Eds.; Springer VS: Wiesbaden, Germany, 2018; pp. 195-209.

26. Schweizer-Ries, P.; Rau, I.; Zoellner, J.; Nolting, K.; Rupp, J.; Keppler, D. Aktivität und Teilhabe-Akzeptanz Erneuerbarer Energie durch Beteiligung Steigern; Forschungsgruppe Umweltpsychologie: Magdeburg/Berlin, Germany, 2010.

27. von Wirth, T.; Gislason, L.; Seidl, R. Distributed energy systems on a neighborhood scale: Reviewing drivers of and barriers to social acceptance. Renew. Sustain. Energy Rev. 2018, 82, 2618-2628. [CrossRef]

28. Huijts, N.M.A.; Molin, E.J.E.; Steg, L. Psychological factors influencing sustainable energy technology acceptance: A review-based comprehensive framework. Renew. Sustain. Energy Rev. 2012, 16, 525-531. [CrossRef]

29. Wunderlich, C. Akzeptanz und Bürgerbeteiligung für Erneuerbare Energien. Erkenntnisse aus Akzeptanz-und Partizipationsforschung. Available online: https://www.energiewende-sta.de/wp-content/ uploads/2011/09/AEE_Akzeptanz-und-B\%c3\%bcrgerbeteiligung-EE.pdf (accessed on 22 April 2020).

30. Mast, C.; Stehle, H. Energieprojekte im Offentlichen Diskurs: Erwartungen und Themeninteressen der Bevölkerung; 1. Auflage 2016; Springer VS: Wiesbaden, Germany, 2016; ISBN 978-3-658-12710-7.

31. Jones, C.R.; Gaede, J.; Ganowski, S.; Rowlands, I.H. Understanding lay-public perceptions of energy storage technologies: Results of a questionnaire conducted in the UK. Energy Procedia 2018, 151, 135-143. [CrossRef]

32. Agnew, S.; Dargusch, P. Consumer preferences for household-level battery energy storage. Renew. Sustain. Energy Rev. 2017, 75, 609-617. [CrossRef]

33. Gährs, S.; Mehler, K.; Bost, M.; Hirschl, B. Acceptance of ancillary services and willingness to invest in PV-storage-systems. Energy Procedia 2015, 73, 29-36. [CrossRef]

34. Graebig, M.; Erdmann, G.; Röder, S. Assessment of Residential Battery Systems (RBS): Profitability, Perceived Value Proposition, and Potential Business Models; Technische Universität Berlin: Berlin, Germany, 2014.

35. Figgener, J.; Haberschusz, D.; Kairies, K.-P.; Wessels, O.; Tepe, B.; Sauer, D.U. Wissenschaftliches Mess- und Evaluierungsprogramm Solarstromspeicher 2.0; Annual Report; RWTH Aachen: Aachen, Germany, 2018.

36. Smale, H.; Rowlands, I.H.; Gaede, J. A Gap Analysis. Community Acceptance of Energy Storage Projects; University of Waterloo: Waterloo, Canada, 2017.

37. Wawer, T.; Griese, K.-M.; Halstrup, D.; Ortmann, M. Stromspeicher im Quartier: Aktuelle Herausforderungen und Geschäftsmodelle in Deutschland. Z. Für Energiewirtschaft 2018, 42, 225-234. [CrossRef]

38. MVV Energie AG; Universität Stuttgart; Netrion; ADS-TEC. Strombank-Innovatives Betreibermodell für Quartierspeicher. 2016. Available online: http://fachdokumente.lubw.baden-wuerttemberg.de/servlet/is/ 120150/bwe13017_13020.pdf?command=downloadContent\&filename=bwe13017_13020.pdf\&FIS=203 (accessed on 22 April 2020).

39. Graulich, K.; Hilbert, I.; Heinemann, C. Einsatz und Wirtschaftlichkeit von Photovoltaik-Batteriespeichern in Kombination mit Stromsparen. Kurzinformation für Verbraucherinnen und Verbraucher; Öko-Institut e.V.: Freiburg, Germany, 2018.

40. Geelen, D.; Reinders, A.; Keyson, D. Empowering the end-user in smart grids: Recommendations for the design of products and services. Energy Policy 2013, 61, 151-161. [CrossRef]

41. Schnabel, F.; Kreidel, K. Dienstleistungen für Gemeinschaftlich Genutzte Quartierspeicher; Fraunhofer-Institut für Arbeitswirtschaft und Organisation IAO: Stuttgart, Germany, 2019.

42. Parra, D.; Swierczynski, M.; Stroe, D.I.; Norman, S.A.; Abdon, A.; Worlitschek, J.; O’Doherty, T.; Rodrigues, L.; Gillott, M.; Zhang, X.; et al. An interdisciplinary review of energy storage for communities: Challenges and perspectives. Renew. Sustain. Energy Rev. 2017, 79, 730-749. [CrossRef] 
43. ENTEGA. Besser Wachsen. Geschäftsbericht 2018; ENTEGA: Darmstadt, Germany, 2018.

44. ENTEGA. Besser Handeln. Nachhaltigkeitsbericht 2018; ENTEGA: Darmstadt, Germany, 2018.

45. Statista. Länge der Versorgungsunterbrechung je Stromverbraucher in Deutschland in den Jahren 2006 bis 2018 ; Statista GmbH: Hamburg, Germany, 2019.

46. Gährs, S.; Knoefel, J.; Cremer, N. Politische Zielsetzungen und Rechtlicher Rahmen für Quartierspeicher-Bestandsaufnahme der Aktuellen Rahmenbedingungen und Diskurse. 2018. Available online: https://www.esquire-projekt.de/data/esquire/Datein/Arbeitspapier_Politische_Zielsetzungen_und_ rechtlicher_Rahmen_fuer_Quartierspeicher-aktualisiert.pdf (accessed on 25 March 2020).

(C) 2020 by the authors. Licensee MDPI, Basel, Switzerland. This article is an open access article distributed under the terms and conditions of the Creative Commons Attribution (CC BY) license (http://creativecommons.org/licenses/by/4.0/). 